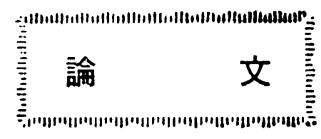

\title{
等色関数個人間変動の生理的要因
}

\author{
専門会員 納谷 嘉信* 伊藤 通* 松本 佳男* \\ 正 会 員 高浜幸太郎** 正会員 側垣 博明**
}

\section{Physiological Causes on Individual Variations of Color-Matching Functions}

\author{
Yoshinobu Nayatani (Fellow Member) Tohru Ito, Yoshio Matsumoto \\ Koutarou Takahama (Member) Hiroaki Sobagaki (Member)
}

\begin{abstract}
The present study confirms that the individual variations of the Stiles' 20 color-matching functions are physiologically well predicted by those of eye-lens and macular optical densities. The principal-component analysis of the blue colormatching functions shows the significance of the two independent spectral components, which are expected to correspond to lens and macular optical densities. The lens and macular densities for each of the Stiles' 20 observers are estimated by using their published data physiologically measured. The estimated densities well predict each of the Stiles' 20 colormatching functions. The singular-value decomposition of the estimated 20 color-matching functions gives a good estimate to the standard-deviate observer derived from the original Stiles 20 color-matching functions by using the same procedure.
\end{abstract}

\section{I. 序論}

観測者メタメリズム指数は, 標準の光拈よび標準観測者に阅し て条件等色をなすサンプル対を，实正常観測者群が観測したとき に生ずる等色のくずれの程度を評価する指数である．これは正常 観測者群の条件等色洋関する等色判断の変動を定める基本的な指 数であり，また照明光の変化によって生ずる条件等色のくずれ， すなわち光メタメリズム指数の評価の指標にもなる1).

観測者メタメリズムの評価基準の制定に向けて, CIE TC-1.07 観測者メタメリズム小委員会は, 1967 年以来, 研究を進めて抒 り，現在その勧告案が完成されようとしている．観測者メタメリ ズム評価は Stiles $^{2)} ら の 20 人 の 10^{\circ}$ 視野に対する等色関数に基つ” いて研究が進められて来た. Wyszecki ${ }^{3)}$ は, これらの 20 人を用 いる平均観測者メタメリズム指数を提案した。 その後, 観測者を 20人よりも少人数で代表して, Wyszecki の平均指数と良相関を 与之ようとする研究が Allen ${ }^{4)}$, Strocka ${ }^{5)}$, 納谷・高浜・側垣 ${ }^{6)}$ および大田7 らにより行なわれた。笔者らの方式( は僄準観測者 および標準偏差観測者の二つの等色関数を用い, 標準の光および 標準観測者に関して条件等色をなすサンプル対において, 標準観

* 大阪奄気通信大学工学部経営工学科

** 笛子技術総合研究所大臤支所
测者から標準偏差観測者に変更した場合の条件等色のくずれを色 差で計算し，それを観測者メタメリズム指数と定めている.

この方式は, Stiles らの20人の全等色関数を用いる Wyszecki の平均観测者メタメリズム指数之良好な相関を与えるだけでな ${ }^{6}$ ，多数の実観測者拈よび Davidson-Hemmendinger の Color Rule を用いる条件等色の個人間変動の史測結果 ${ }^{8 / 9}$ ともよく対応 することが判明している10).

残された課題は, Stiles らの20人の等色関数の変動に対する生 理的基礎を榆討することである。すなわち，それらの等色関数の 個人差が，眼球表面から視細胞に至る光学系の平均特性と，その 個人間変動汇よってどの程度説明し得るかということである.

\section{2. 等色関数 $\bar{b}_{p}(\lambda)$ に関する分析}

まず，各钼測者の短波長側等色閶数 $\bar{b}_{p}(\lambda)$ を解析する，解析 には主成分分析を用いた。ここで源字 $p$ は観測者番号を表わし， $p=1,2, \cdots, 20$ である，解析に先だって，各観測者ごとに次の 基集化を行なう。

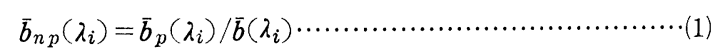

ただし $, p=1,2, \cdots, 20 ; \lambda_{1}=390 \mathrm{~nm}, \quad \lambda_{2}=400 \mathrm{~nm}, \cdots, \lambda_{17}=550$ $\mathrm{nm}$ であり, 解析する波長範围は $390 \mathrm{~nm}$ から $550 \mathrm{~nm}$ の間に限 定した。 そのとき， $\left[\bar{b}_{n p}\left(\lambda_{i}\right)\right]$ は $20 \times 17$ の行列を楧成する.なお，

$$
\ddot{\vec{b}}\left(\lambda_{i}\right)=\frac{1}{20} \sum_{p=1}^{20} \vec{b}_{p}\left(\lambda_{i}\right)
$$

は平均観測者の短波長側等色関数である. 波長範囲を 390 5 50 
$\mathrm{nm}$ に限定して解析したのは次の理由による.すなわち, 波長 $\lambda>550 \mathrm{~nm}$ においては, $\overline{\bar{b}}(\lambda)$ の值はきわめて低くほぼゼ口に近 い. この領域では $\bar{b}_{n p}(\lambda)$ の值の変動は大きく, ほとんど観測譟 差に支配される．このため，(1)式の主成分分析を，波長 $\lambda=390$ 〜 720 nm で実施することは, 詿差の影響のため寄与率の低下を 来たすという理由による．また，生理的要因とされる水晶体拉よ び黄斑色素の光学密度の值が, 波長 $\lambda>550 \mathrm{~nm}$ で汪とんど变化 しないという情報 ${ }^{11)}$ に基づく.

観測者 $p$ に関するべクトル $\left[\bar{b}_{n p}\left(\lambda_{1}\right), \bar{b}_{n p}\left(\lambda_{2}\right), \cdots, \bar{b}_{n p}\left(\lambda_{17}\right)\right]$ は, 観測者 $p$ と平均観測者の等色関数の比であり, 両観測者の眼 球表面から錐状体までの相対分光透過率比を示す.なお $\bar{b}_{n p}\left(\lambda_{i}\right)$ はその構成上すべての観測者について, 波長 $\lambda=444.4 \mathrm{~nm}$ で 1 となるよう基準化されている。すなわち次式が成立する。

$$
\vec{b}_{n p}(444.4)=1
$$

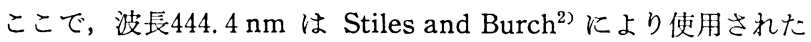
青原刺激の波長の值である.

$\bar{b}_{n p}\left(\lambda_{i}\right)$ のデータ用いて, 波長間の分散・共分散行列 $\left[V_{i j}\right]$ に 基づいて主成分分析を行なった。 ただし，行列要素 $V_{i j}$ は次式 で与えられる。

$$
\begin{gathered}
V_{i j}=\frac{1}{19} \sum_{p=1}^{20}\left\{\bar{b}_{n p}\left(\lambda_{i}\right)-1\right\}\left\{\bar{b}_{n p}\left(\lambda_{j}\right)-1\right\} \\
(i, j=1,2, \cdots, 17)
\end{gathered}
$$

主成分分析の結果, 第 1 主成分の寄与率は $74.3 \%$, 第 2 主成分 の奇与率は $20.7 \%$, 雨者の累積寄与率は $95.0 \%$ となった。第 3 主

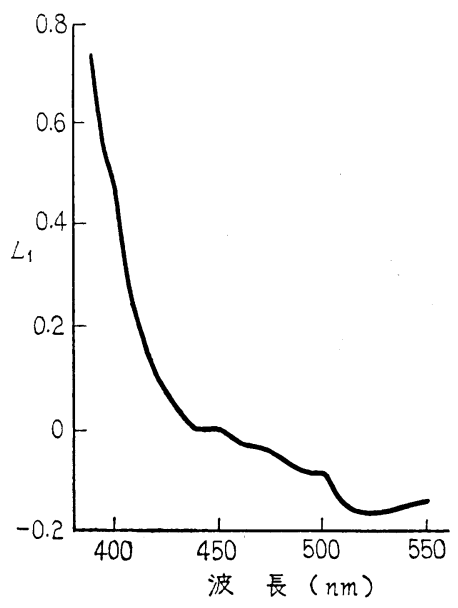

图 1 第 1 固有ベクトルの分光特性

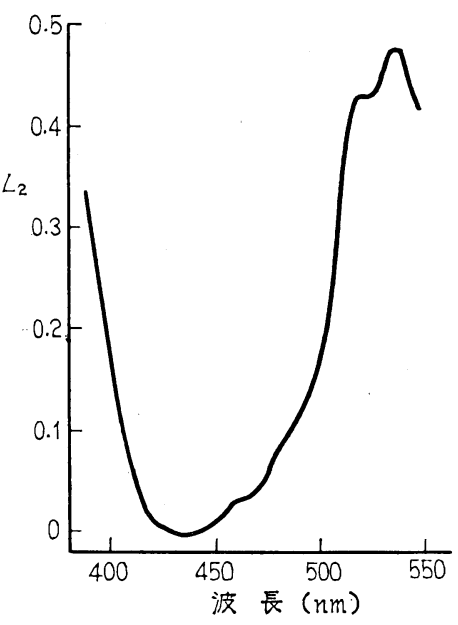

因 2 第 2 固有ベクトルの分光特性
成分以下の奇与率は小さく無視できる，すなわち， $\bar{b}_{n p}(\lambda)$ の钼 測者間変動は二つの独立な生理的要因からなることを示㖫する.

図 1 拉よび図 2 亿第1固有ベクトル拈よび第 2 固有ベクト ルを示す。これらと公刊されている水晶体および黄斑色素の光学 密度の分光物性 ${ }^{11)}$ との比較は, 第 1 固有ベクトルが水晶体の分光 透過率に，第 2 固有ベクトルが黄斑色素の分光密度に関係するこ とを示唆する。
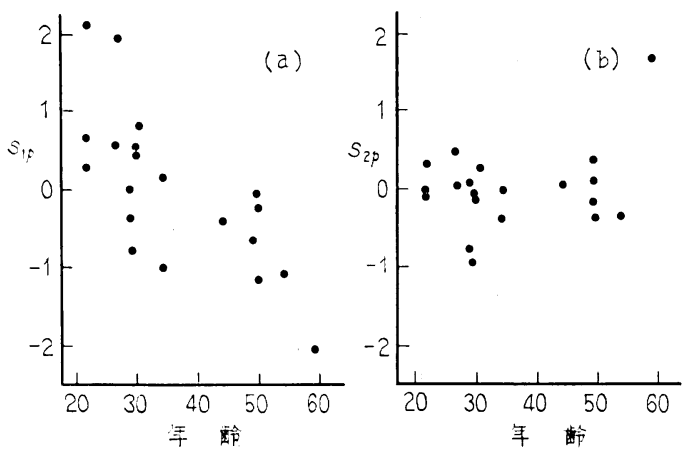

図 3 観測者の年夦と(a)策 1 主成分得点 $s_{1 p}$, および(b)第 2 主成分得点 $s_{2 p}$ の跀

図 $3(\mathbf{a})$ ，(b) 飞第 1 および第 2 主成分得点と年路の関係を示 す. 水晶体の特性を代表すると思われる，第 1 成分の待点が年齢 と明確な相関を示し，一方，第 2 主成分は無相関である。第 1 主 成分の寄与率の高いことより，等色関数は年秢によって系統的变 化を示すことが同われる.

\section{3. 生理情報による $\bar{b}_{n p}(\lambda)$ の推定}

前節の結果, $\bar{b}_{n p}(\lambda)$ の個人間変動は 2 種の独立な成分からな ることが推測された，そこで，水晶体抢よび黄斑色素の公刊值 ${ }^{11)}$ を用いて，次式で $\bar{b}_{n p}(\lambda)$ を推定した。

$$
\begin{aligned}
\tilde{b}_{n p}(\lambda)= & 10 * *\left[k_{1 p}\left\{D_{1}(\lambda)-D_{1}(444.4)\right\}\right. \\
& \left.+k_{2 p}\left\{D_{2}(\lambda)-D_{2}(444.4)\right\}+\varepsilon_{p}(\lambda)\right]
\end{aligned}
$$

ここで，**は指数演算子であり，**以降は10の置指数を示す. $D_{1}(\lambda)$ は水晶体の分光密度, $D_{2}(\lambda)$ は黄斑色素の 分光密度を示 す. $D_{1}(444.4), D_{2}(444.4)$ は $\bar{b}_{n p}(\lambda)$ の基準化波長 $444.4 \mathrm{~nm}$ に 打ける分光密度の值である. $k_{1 p}$ 㧊よび $k_{2 p}$ は水晶体および黄斑 色素の分光密度の個人差を示す係数である. $\varepsilon_{p}(\lambda)$ は残差に対応 する. (5)式は平均観测者 $\left(b_{n p}(\lambda)=1\right)$ に対応して $k_{1 p}=k_{2 p}=0$, また $\lambda=444.4 \mathrm{~nm} に$ 打いて, $b_{n p}(\lambda=444.4)=1$ がすべての観測 者について成立することが期待される.

$k_{1 p}$ 㧊よび $k_{2 p}$ の推定值 $\hat{k}_{1 p}$ 㧊よび $\hat{k}_{2 p}$ を，(5)式の両辺の対数 を取り各観測者ごとに最小自乗法により求めた。たたし，計算は 波長範囲 390〜550 nm にわたって行なった．ここで， $D_{1}(444.4)$ $=0.247, D_{2}(444.4)=0.428$ はそれぞれ補間により定めた。第 2 節で求めた $s_{1 p}, s_{2 p}$ と $\hat{k}_{1 p}, \hat{k}_{2 p}$ の対応する散布図を図 4 に示 す. それぞれ相関の存在を示す。すなわち $\bar{b}_{n p}(\lambda)$ は， 2 種の生 理的要因の寄与に上り精度よく推定し得ることが判明した。

$\mathrm{MCB}$ (27藏), EA (28藏), WSS (54歳) の 3 人の観测者につ いて，それぞれの $\bar{b}_{n p}(\lambda) を \hat{k}_{1 p}, \hat{k}_{2 p}, D_{1}(\lambda), D_{2}(\lambda)$ 等の值を 用いて推定した。图 5 にそれぞれ実測值（実線）之推定值（点 線）により比較して示す。両者は良好な一致を示している。すべ ての観測者についても両者の比較は，括招む称良好な一致を示し た.

図 1 および図 2 の固有べクトルが，主成分分析といら固有べク 

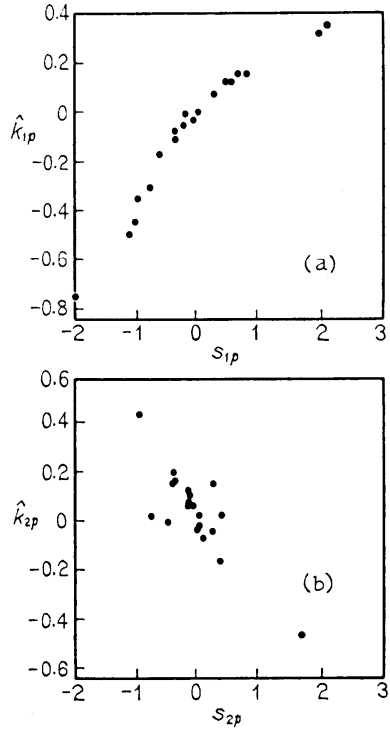

図 4 (a)第 1 主成分得点 $s_{1 p}$ と水品 体扣上び黄斑色菜の侗人羊

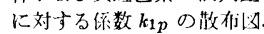
(b)第 2 主成分得点 $s_{2 p}$ と水品

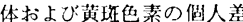
に対する係数 $k_{2 p}$ の㪄布 四.

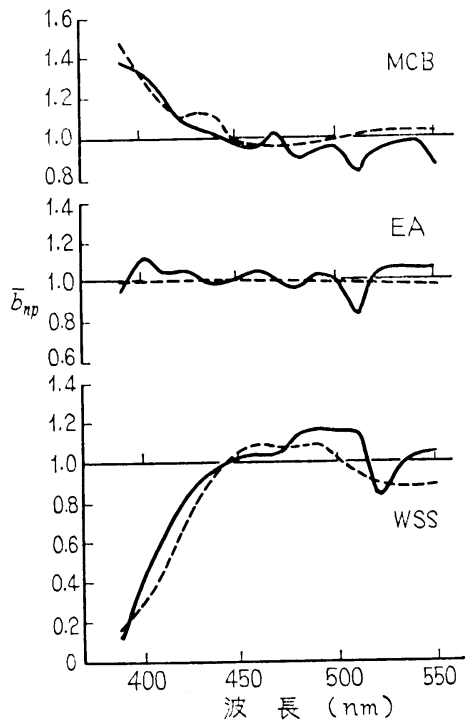

图 53 名の锶測者に対与る $\bar{b}_{n p}(\lambda)$ 関 数の比㜞

困中，尖線は実測闺呚，点楾は 水晶体および黄班色菜の分光密度 より子測した関数を示与.

トル間の直交性に基礎をおく数学的解析にもかかわらず，それぞ れ水晶体特よび黄斑色素の分光密度と類似な形状を示したのは, 次の理由によると思われる.すなわち水晶体扣よび黄斑色素の分 光密度 $D_{1}(\lambda)$ と $D_{2}(\lambda)$ を波長範囲 $400 \sim 570 \mathrm{~nm}$ と定めた場合の

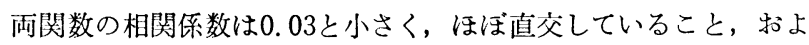
び両者の寄与の大きな差によるものと考兄られる。な和第 3 節以 降は，すべて第 2 節の主成分分析で尊かれた量と無関係な量であ る $D_{1}(\lambda)$ 打よび $D_{2}(\lambda)$ を用いて解析を行なっている。このため 主成分分析の結果は直接には本報の結論に影響しない.

\section{4. 生理情報による $\bar{g}_{n p}(\lambda)$ および $\overline{\boldsymbol{r}}_{n p}(\lambda)$ の推定}

すでに $\bar{b}_{n p}(\lambda), D_{1}(\lambda), D_{2}(\lambda)$ に基ついて $k_{1 p}, k_{2 p}$ を推定し
た. 推定値 $\hat{k}_{1 p}, \hat{k}_{2 p}$ はそれぞれ水晶体扣よび 黄斑色素の分光密 度の観測者間変動を示す係数である。

ところで, $D_{1}(\lambda), D_{2}(\lambda), \hat{k}_{1 p}, \hat{k}_{2 p}$ が観測者について固有の 特性であるなら，これらの值は， $\bar{g}_{n p}(\lambda)=\bar{g}_{p}(\lambda) / \overline{\bar{g}}(\lambda)$ 打よび $\bar{r}_{n p}(\lambda)=\bar{r}_{p}(\lambda) / \ddot{r}(\lambda)$ の推定にも当然用いることができる.すな わち, 各観測者ごとの水晶体および黄斑色素の分光密度の变動 は，すべての錐状体に其通の影響を持つはずであり，各等色関数 への影響も共通である。

なお， $\bar{g}_{n p}(\lambda)$ および $\bar{r}_{n p}(\lambda)$ のそれぞれの基準化波長 $\lambda_{g}=$ $526.3 \mathrm{~nm}$ 扣よび $\lambda_{r}=645.2 \mathrm{~nm}$ を考虑して， $\bar{g}_{n p}(\lambda)$ および $\bar{r}_{n p}(\lambda)$ の推定を次式で行なった。 これらの波長は Stiles and Burch $^{2)}$ により使用された緑および赤原刺激の值である.

$$
\begin{aligned}
<\bar{g}_{n p}(\lambda)>= & 10 * *\left[\hat{k}_{1 p}\left\{D_{1}(\lambda)-D_{1}\left(\lambda_{g}\right)\right\}\right. \\
& \left.+\hat{k}_{2 p}\left\{D_{2}(\lambda)-D_{2}(\lambda)\right\}\right] \cdots \\
<\bar{r}_{n p}(\lambda)>= & 10 * *\left[\hat{k}_{1 p}\left\{D_{1}(\lambda)-D_{1}\left(\lambda_{r}\right)\right\}\right. \\
& \left.+\hat{k}_{2 p}\left\{D_{2}(\lambda)-D_{2}\left(\lambda_{r}\right)\right\}\right] \cdots
\end{aligned}
$$

ここで, 記号く〉は推定值の意味である. 計算に用いる $\hat{k}_{1 p}$, $\hat{k}_{2 p}$ は第 3 節で推定した值を使用した. $D_{1}(\lambda), D_{2}(\lambda)$ も同様に公 刊值 ${ }^{11)}$ 用いた。ただし， $D_{1}\left(\lambda_{g}\right)=0.0936 ， D_{1}\left(\lambda_{r}\right)=0.0029$, $D_{2}\left(\lambda_{g}\right)=0.0180, D_{2}\left(\lambda_{r}\right)=0$ 等の值は補間して定めた.
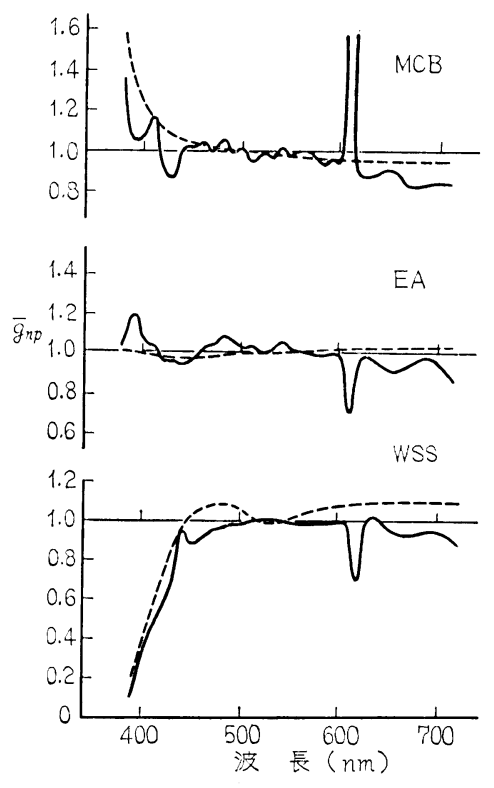

图 63 名の観测者化対する $\vec{g}_{n p}(\lambda)$ 関数 の比較

内中，実線注椠湖阅数，点楾は水

晶体および黄玫色素の分光密度より

子測した関数を示す。

図 5 の 3 人の観測者について，図 6 に $\bar{g}_{n p}(\lambda)$ の尖測值（哭 線）と推定值点線の比䡆を，そして図 7 に $\bar{r}_{n p}(\lambda)$ の実测值 (笑線) と推定值 (点線) の比較を示す。図 5 から図 7 に見られ るように 3 人の観測者について，史測值と推定値は注注良好な一 致を示している．さらに全観测者についても実測值と推定值の間 に良好な刘応が認められた。

以上のことから次の事柄が結論される.

(1) $\bar{r}_{n p}(\lambda), \bar{g}_{n p}(\gamma), \bar{b}_{n p}(\lambda)$ の個人間変動は，水晶体拈よび 黄琣色素の分光密度の個人差に基づく眼球表面から視細胞に至る 光学系の分光透過率変動で，十分精度よく説明することができ る.

(2) (1)項扣よび第 2 節の主成分分析結果より，錐状体自身の分 


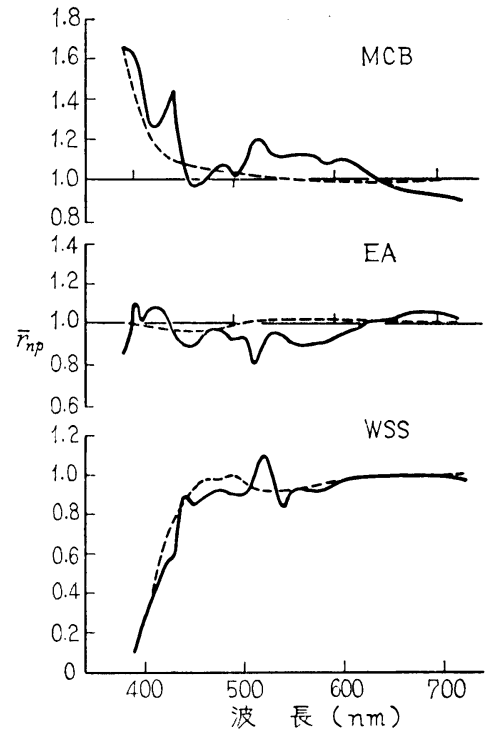

图 73 名の観測者に対する $\bar{r}_{n p}(\lambda)$ 闺数 の比較

刚中，実線は实测関数，点線は水 唱休㧍よび黄斑色菜の分光密度より 子测した閔数を示す.

光感度特性の個人差はきわめて小さいことが推測される。

な打原因不明であるが， Stiles らの20人の等色関数表 ${ }^{32}$ 亿打い て, $\bar{g}_{n p}(\lambda)$ 関数が $\lambda=620 \mathrm{~nm}$ で特異な変動を含むことが図 6 よ り伺われる.この状況は他の観測者についても同様であった。

\section{5. 光学密度を用いる等色関数の推定とその特異值分解}

水晶体扣よび黄斑色素の分光密度の観測者間変動でもって, Stiles らの 20 人の等色関数の個人差が十分精度よく説明し得るこ とを示した. その結果, Stiles らの 20 人の等色関数の, 平均等色 関数からの偏差 $\Delta \vec{r}_{p}(\lambda), \Delta \bar{g}_{p}(\lambda), \Delta \bar{b}_{p}(\lambda)$ の推定值は次式で推 定することができる.

$$
\begin{aligned}
<\Delta \bar{r}_{p}(\lambda)>= & \bar{r}(\lambda)\left[1 0 * * \left[\hat{k}_{1 p}\left\{D_{1}(\lambda)-D_{1}\left(\lambda_{r}\right)\right\}\right.\right. \\
& \left.\left.+\hat{k}_{2 p}\left\{D_{2}(\lambda)-D_{2}\left(\lambda_{r}\right)\right\}\right]-1\right] \cdots \\
<\Delta \bar{g}_{p}(\lambda)>= & \bar{g}(\lambda)\left[1 0 * * \left[\hat{k}_{1 p}\left\{D_{1}(\lambda)-D_{1}\left(\lambda_{g}\right)\right\}\right.\right. \\
& \left.\left.+\hat{k}_{2 p}\left\{D_{2}(\lambda)-D_{2}\left(\lambda_{g}\right)\right\}\right]-1\right] \cdots \\
<\Delta \bar{b}_{p}(\lambda)>= & \overline{\bar{g}}(\lambda)\left[1 0 * * \left[\hat{k}_{1 p}\left\{D_{1}(\lambda)-D_{1}\left(\lambda_{b}\right)\right\}\right.\right. \\
& \left.\left.+\hat{k}_{2 p}\left\{D_{2}(\lambda)-D_{2}\left(\lambda_{b}\right)\right\}\right]-1\right] \cdots
\end{aligned}
$$

ただし $p=1,2, \cdots, 20 ; \lambda=390,400, \cdots, 720 \mathrm{~nm}$ である.

さらに, $\left\langle\bar{r}_{p}(\lambda)\right\rangle,\left\langle\Delta \bar{g}_{p}(\lambda)\right\rangle,\left\langle\bar{b}_{p}(\lambda)\right\rangle$ CIE 1964 表色 系に持沙る RGB 系から XYZ系への変換式 ${ }^{12)}$ 用いて, これら を各観測者の偏差等色関数の推定值 $\left\langle\Delta \bar{x}_{p}(\lambda)\right\rangle,\left\langle\Delta \bar{y}_{p}(\lambda)\right\rangle$, $<\Delta \bar{z}_{p}(\lambda)>$ に変換した (足字10は省略). この結果, 次のマトリ ックスが構成される.

$$
\begin{aligned}
& {\left[m_{p} \lambda\right]=\left[\begin{array}{c}
m_{1,1}, \cdots \cdots, m_{1,102} \\
\cdots \cdots \\
m_{20,1}, \cdots \cdots, m_{20,102}
\end{array}\right]} \\
& =\left[\begin{array}{c}
\left\langle\Delta \bar{x}_{1}(390)\right\rangle, \cdots,\left\langle\bar{x}_{1}(720)\right\rangle .\left\langle\Delta \bar{y}_{1}(390)\right\rangle, \\
\cdots \cdots \cdots \cdots \cdots \cdots \cdots \cdots \cdots \cdots \cdots \cdots \cdots \cdots \cdots \cdots \cdots \\
\left\langle\Delta \bar{x}_{20}(390)\right\rangle, \cdots,\left\langle\bar{x}_{20}(720)\right\rangle,\left\langle\Delta \bar{y}_{20}(390)\right\rangle,
\end{array}\right. \\
& \left.\cdots, \Delta \bar{y}_{1}(720)\right\rangle,\left\langle\Delta \bar{z}_{1}(390)\right\rangle, \cdots,\left\langle\Delta \bar{z}_{1}(720)\right\rangle \\
& \cdots,\left\langle\Delta \bar{y}_{20}(720)>,\left\langle\Delta \bar{z}_{20}(390)\right\rangle, \cdots,\left\langle\Delta \bar{z}_{20}(720)\right\rangle\right.
\end{aligned}
$$

文献(6)と同様な特異值分解法 ${ }^{13)}$ を,(11)式の行列に適用して推定偏
差等色関数からの偏差関数群 $\left\langle\alpha^{(1)}(\lambda)\right\rangle, \quad\left\langle\beta^{(1)}(\lambda)\right\rangle$, $\left\langle\gamma^{(1)}(\lambda)\right\rangle$ ，扣上び係数 $\left\langle C^{(1)}{ }_{p}\right\rangle$ を求めることができる。 そ して, これらの結果に基づき実測および推定等色関数より求めた 2 種の偏差観測者関数間の比較を行ならことが可能となる。これ により，観測者個々の等色関数の実測值と推定值の比較よりも総 合的な比較を行ならことができる。

さて(11)式の特異值分解の結果は，第 1 成分の寄与率は $83.6 \%$, 第 2 成分の寄与率は $15.6 \%$ となり，第 2 成分までの累積寄与率は $99.2 \%$ を及几だ．第 3 成分以下の寄与は全く小さい，一方，史 测等色関数を用いたときの特異值分解では，第 1 成分の寄与率 は $56.4 \%$, 第 2 成分の寄与率は $17.2 \%$, 第 3 成分は $10.4 \%$ あっ た ${ }^{6}$. 推定関数に対する特異值分解で主要成分の寄与事が高いこ とは，それが水晶体拉よび黄斑色素の分光密度の 2 成分だけを考 虑し，観测䛊差を含まないことの反映であると考えられる。

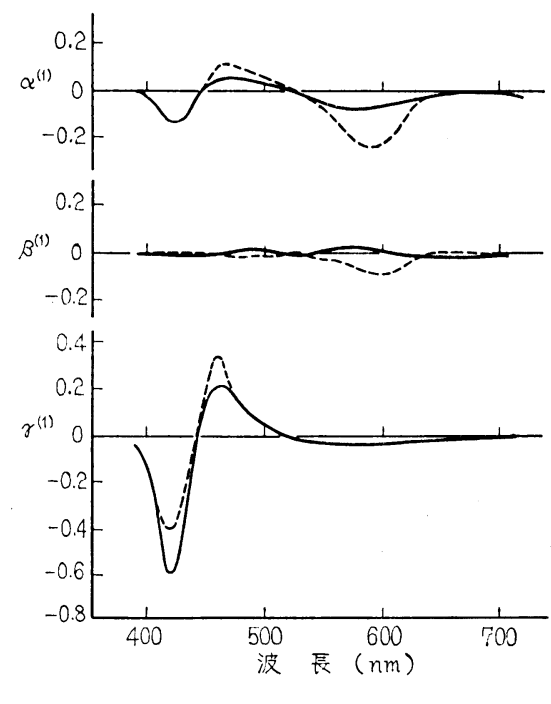

图 $8 \alpha^{(1)}(\lambda), \beta^{(1)}(\lambda), \gamma^{(1)}(\lambda)$ と $\left\langle\alpha^{(1)}(\lambda)\right\rangle$, $\left\langle\beta^{(1)}(\lambda)\right\rangle,\left\langle\gamma^{(1)}(\lambda)\right\rangle$ の比較 (注) 点線注 $\alpha^{(1)}(\lambda)$ 等を, 实線は $\left\langle\alpha^{(1)}(\lambda)\right\rangle$ 等を示す。

文献(6)では，史測等色関数からの 偏美関数 $\alpha^{(1)}(\lambda), \beta^{(1)}(\lambda)$, $\gamma^{(1)}(\lambda)$, および係数 $C^{(1)} p$ が与兄られている.これらと(11)式より 求めた第 1 成分の推定值 $\left\langle\alpha^{(1)}(\lambda)\right\rangle,\left\langle\beta^{(1)}(\lambda)\right\rangle,\left\langle\gamma^{(1)}(\lambda)\right\rangle$, $\left\langle C_{p}^{(1)}\right\rangle$ とを比較する. 図 8 亿偏差関数の比較を示す. 図の実 線は $\alpha^{(1)}(\lambda), \quad \beta^{(1)}(\lambda), \quad \gamma^{(1)}(\lambda)$ を, 点線は本報で求めた $\left\langle\alpha^{(1)}(\lambda)\right\rangle,\left\langle\beta^{(1)}(\lambda)\right\rangle,\left\langle\gamma^{(1)}(\lambda)\right\rangle$ を示す. きわめて良好な 一致が認められた。 また第 1 成分の等色関数の各観測者ごとの偏 差関数への影響の個人差を示す係数 $C^{(1)}{ }_{p}$ および $\left\langle C^{(1)}{ }_{p}>\right.$ の散 布図を図 9 に示す。両者の間に良好な相関が認められた。

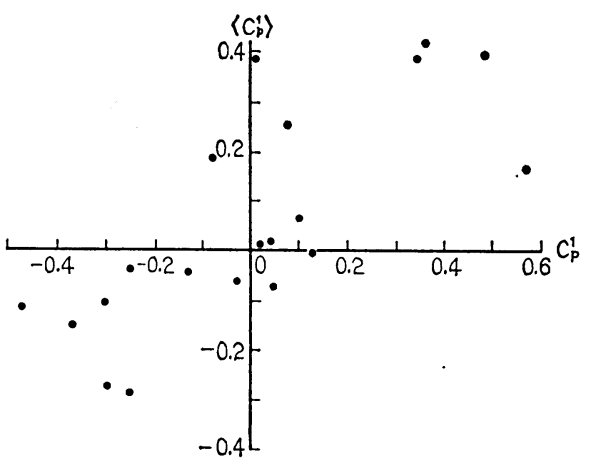

因 $9 C^{(1)} p_{p}<\left\langle C^{(1)}{ }_{p}\right\rangle$ の比㜞 
第 2 成分については, 寄与率が低いことを反映して一致の程度 はやや少るが, $\alpha^{(2)}(\lambda), \beta^{(2)}(\lambda), \gamma^{(2)}(\lambda)$ と $\left\langle\alpha^{(2)}(\lambda)>\right.$, $\left\langle\beta^{(2)}(\lambda)\right\rangle,\left\langle\gamma^{(2)}(\lambda)\right\rangle$ 形状の相似性が把握された。

\section{6. 結 論}

Stiles らの 20 人の等色関数が, 水晶体および黄斑色素の分光密 度の観測者間変動により, 十分精度よく推定可能であることが判 明した。この結果 Stiles らの 20 人の等色関数の観測者間変動の 生理的基礎がほぼ確立されたと考えてよい。 また Stiles らの20 人の等色関数の元となった 53 人の等色関数を, TC-1.07の委員長 大田登博士より入手している．53人の等色関数を用いる钼測者入 タメリズム指数は，20人の観測者メタメリズム指数と良好な相関 を示す．しかし53人の観測者の年齢分布が若年層に偏ること, 観 測䛊差の大きいと思われる観測者も混入していることなどのた め, 53 人の等色関数の特買値分解に上る第 1 , 第 2 成分などの泭 与率はやや低い.

これらの比較の詳細は別途報告の予定である.ささらに53人の等 色関数が末公刊資料であることなどを考虑すれば， Stiles らの20 人の等色関数を観測者メタメリズム指数を定義するための母観测 者群と考えることが適当であろう.

以上の結果, 筆者らの既報の砸究6)10) 抢よび本研究を組又合わ せることにより，観測者メタメリズム指数の評価方法に関与る国 際勧告の基礎がほぼ確立されたといえよう。

\section{文献}

(1) Berger, A. and Strocka, D.: Quantitative assessment of artificial light sources for the best fit to standard illuminant D65, Appl. Opt., 12, (1973) 338 348.

(2) Stiles, W. S. and Burch, J. M.: NPL colour-matching investigation; Final Report Optica Acta, 6 (1959) 1
26

(3) Wyszecki, G.: The degree of color metamerism and its specification, Textile Chemist \& Colorist, 1 (1969) 12

(4) Allen, E.: An index of matamerism for observer differences, Proc. 1st AIC Cong. COLOR 69, Musterschmidt, Göttingen, (1970) 771 784

(5) Strocka, D.: Possibilities for specifying an index of observer metamerism, Proc. 3rd AIC Cong., COLOR 77, Adam Hilger, Bristol, (1978) 432 436

(6) Nayatani, Y., Takahama, K. and Sobagaki, H.: A proposal of new standard deviate observer, Color Res. Appl., 8 (1983) 47 56

(7) Ohta, N.: Formulation of a standard deviate observer by a nonlinear optimization technique, Color Res. Appl., 10, (1985) 156 164

(8) Kaiser, P.K. and Hemmendinger, H.: The color rule; A device for color-vision testing, Color Res. Appl.

(9) Billmyer, F. W., Jr. and Saltzman, M.: Observer metamerism Color Res. Appl. 5 (1980) 72

(10) Nayatani, Y., Hashimoto, K., Takahama, K. and Soba gaki, H.: Comparison of methods for assessing observe metamerism, Color Res. Appl., 10 (1985) 149 155

(11) Wyszecki, G. and Stiles, W. S.: Color Science, 2nd ed. Wiley, New York, (1982) 108 112

(12) Wyszecki, G. and Stiles, W. S.: Color Science, 2nd ed. Wiley, New York, (1982) 141

(13) 森 正武, 名取 亮, 鳥居達生：数值計算第 3 章, 岩波講 座 情報科学18, 岩波書店（昭57）

（受付1987年1月 5 日） 